\title{
$\alpha$-Lipoic Acid Modulates Extracellular Matrix and Angiogenesis Gene Expression in Non-Healing Wounds Treated with Hyperbaric Oxygen Therapy
}

\author{
Renata Alleva, ${ }_{1}$ Marco Tomasetti, ${ }^{2}$ Davide Sartini, ${ }^{3}$ Monica Emanuelli, ${ }^{3}$ Emanuele Nasole, ${ }^{4}$ \\ Ferruccio Di Donato, ${ }^{4}$ Battista Borghi, ${ }^{1}$ Lory Santarelli, ${ }^{2}$ and Jiri Neuzil ${ }^{5,6}$
}

${ }^{1}$ Department of Anesthesiology, IRCCS Istituti Ortopedici Rizzoli, Bologna, Italy; ${ }^{2}$ Department of Molecular Pathology and Innovative Therapies, Polytechnic University of Marche, Ancona, Italy; Institute of Biochemical Biotechnologies, Polytechnic University of Marche, Ancona, Italy; ${ }^{4}$ Hyperbaric Center, MPM, Bologna, Italy; ${ }^{5}$ Apoptosis Research Group, School of Medical Science, Griffith University, Southport, Qld, Australia; ${ }^{6}$ Molecular Therapy Group, Institute of Molecular Genetics, Academy of Sciences of the Czech Republic, Prague, Czech Republic

\begin{abstract}
$\alpha$-Lipoic acid (LA) has been found previously to accelerate wound repair in patients affected by chronic wounds who underwent hyperbaric oxygen ( $\mathrm{HBO}$ ) therapy. Because proteinases are important in wound repair, we hypothesized that LA may regulate matrix metalloproteinase (MMP) expression in cells that are involved in wound repair. Patients undergoing HBO therapy were double-blind randomized into two groups: the LA group and the placebo group. Gene expression profiles for MMPs and for angiogenesis mediators were evaluated in biopsies collected at the first HBO session, at the seventh HBO session, and after 14 days of HBO treatment. ELISA tests were used to validate microarray expression of selected genes. LA supplementation in combination with HBO therapy downregulated the inflammatory cytokines and the growth factors which, in turn, affect MMPs expression. The disruption of the positive autocrine feedback loops that maintain the chronic wound state promotes progression of the healing process.
\end{abstract}

Online address: http://www.molmed.org

doi: 10.2119/2007-00095.Alleva

\section{INTRODUCTION}

Wound healing is a complex process that proceeds through a number of welldefined and orchestrated stages: inflammation, proliferation, matrix deposition, and remodeling $(1,2)$. Enzymatic remodeling of the extracellular matrix (ECM) is considered essential for proper wound healing (3). Various types of proteinases are implicated in ECM degradation, with the major enzymes represented by matrix metalloproteinases (MMPs). MMPs are members of the Zn-dependent endopeptidase family (4), with very low steady-state activity, and their expression is transcriptionally controlled by inflammatory cytokines, growth fac- tors, hormones, and cell-cell and cellmatrix interactions (5).

Self-resolving inflammation is a normal and necessary prerequisite to fibroblast activation and net matrix synthesis, and this process must be regulated tightly, both temporally and spatially. Imbalances in wound proteases and their inhibitors, because of sustained production of inflammatory mediators and influx of inflammatory cells, prevent matrix synthesis and remodeling, essential for progression to a healed wound $(6,7)$. Chronic wounds arise from recurrent or chronic injuries (that is, intermittent ischemia) and/or low-level bacterial contamination. Once established, positive
Address correspondence and reprint requests to Renata Alleva, Department of Anesthesiology, IRCCS Istituti Ortopedici Rizzoli, via pupilli, 1-40136, Bologna, Italy. Phone: +39071 2206063; Fax: + 39071 2206062; E-mail: renalle@libero.it.

Submitted October 2, 2007; Accepted for publication November 23, 2007; Epub (www. molmed.org) ahead of print December 5, 2007. autocrine feedback loops and ongoing insult maintain the chronic wound state, preventing progression of the healing process.

Hyperbaric oxygen (HBO) therapy has been used successfully for the treatment of non-healing wounds $(8,9)$. The healing effect is due to the local increase in the oxygen gradient, resulting in enhanced angiogenesis, growth factor stimulation (10), and increased local resistance to infection (11). Recently, it has been observed that $\alpha$-lipoic acid (LA) administration in association with $\mathrm{HBO}$ efficiently contributes to accelerated regression of chronic ulcers, acting both as an antioxidant and as a modulator of inflammation (12).

Here, we evaluated the effect of LA on the expression of genes involved in ECM remodeling and angiogenesis in patients affected by chronic wounds treated with HBO. We show that LA supplementation in combination with $\mathrm{HBO}$ therapy down- 
regulated inflammatory cytokines and growth factors that, in turn, affect expression of MMPs, promoting the healing process.

\section{MATERIALS AND METHODS}

\section{Subjects and $\alpha$-Lipoic Acid Supplementation}

Twenty patients (seven males and 13 females, mean age of $77 \pm 9$ years) were enrolled at the Hyperbaric Centre, MPM, Bologna, Italy, after giving their informed consent. The pathologies treated by HBO therapy were ischemic diabetic ulcers $(n=12)$ and ischemic vasculopatic ulcers $(n=8)$, wound area $16.3 \pm 4.2 \mathrm{~cm}^{2}$ (Table 1). The inclusion criteria were non-smokers with ulcers of at least $30 \mathrm{~d}$ old, diabetic feet < stage four according to Wagner, ankle pressure $>50 \mathrm{mmHg}$, basal oxymetry transcute $\left(p \mathrm{TcO}_{2}\right)>20 \mathrm{mmHg}$. Patients with other diseases (inflammatory, rheumatic, and endocrinal diseases) and subjects under pharmacological therapies or antioxidant supplementation were excluded from the study. Patients were doubleblind randomized into two groups, the $\alpha$-Lipoic acid group (LA-group) and the placebo group (PL-group). At the first $\mathrm{HBO}$ session, the subjects received $300 \mathrm{mg}$ of LA (one capsule of Byodinoral 300, MDM, Milano) or placebo (one capsule) $1 \mathrm{~h}$ before oxygen exposure and a second capsule of their respective protocol immediately after the therapy. The patients then received LA or placebo supplementation (two capsules/day) for the next 14 consecutive $\mathrm{HBO}$ treatments (one session/day).

\section{Hyperbaric Protocol}

Patients were exposed to 14 consecutive HBO treatments (one session/day) according to a routine therapy protocol. The multiplace chamber (Sistemi Iperbarici, Ardea, Italy) was pressurized with compressed air where the patients breathed $100 \% \mathrm{O}_{2}$ using a mask at a pressure of 2.5 ATA for a total of three 25-min sessions, interrupted by 3-min intervals of breathing normal air.

Table 1. Characteristics of recruited subjects

\begin{tabular}{lcc}
\hline Characteristics & $\begin{array}{c}\text { PL-group } \\
n=10\end{array}$ & $\begin{array}{c}\text { LA-group } \\
n=10\end{array}$ \\
\hline Age (years) & $79 \pm 9$ & $75 \pm 8$ \\
Sex (M/F) & $3 / 7$ & $4 / 6$ \\
Pathology & 6 & 6 \\
Ischemic diabetic ulcer & 4 & 4 \\
Ischemic vasculopatic ulcer & $15 \pm 3$ & $17 \pm 2$ \\
Wound area $\left(\mathrm{cm}^{2}\right)$ & & \\
\hline
\end{tabular}

\section{Harvesting and Processing of Plasma and Biopsy Samples}

Blood and biopsy samples were taken at the first $\mathrm{HBO}$ session $\left(\mathrm{T}_{0}\right)$, at the seventh $\mathrm{HBO}$ session $\left(\mathrm{T}_{1}\right)$, and after day 14 of the HBO treatment $\left(\mathrm{T}_{2}\right)$. Venous blood samples, collected in heparinized tubes, were centrifuged at $1,000 \mathrm{~g}$ for $15 \mathrm{~min}$ and the plasma obtained stored at $-80^{\circ} \mathrm{C}$ until ELISA analysis. A $5 \mathrm{~mm}$ diameter biopsy was taken from the center of the wound. The first sample was stored in the RNAlater RNA stabilization reagent (Ambion, Austin, TX, USA) and stored at $-20^{\circ} \mathrm{C}$ until the microarray analysis was performed. The second biopsy sample was immediately frozen at $-20^{\circ} \mathrm{C}$. Frozen biopsies were homogenized in the lysis buffer (50 mM Tris-HCl, 1\% Triton X-100, $\mathrm{pH}$ 7.4) and centrifuged at $12,000 \mathrm{~g}$ for 5 min to remove particulate matter. The supernatant was assessed for protein content using the Bradford method (Sigma, St Louis, CA, USA) and stored at $-80^{\circ} \mathrm{C}$ until ELISA analysis.

\section{Total RNA Isolation}

Total RNA was isolated from biopsy samples using a Total RNA purification kit (Versagene, Gentra Systems, Minneapolis, MN, USA). The integrity of the obtained RNA was evaluated by electrophoresis, and RNA concentration and purity was determined by UV spectrophotometry.

\section{Microarray Analysis}

The Oligo GEArray series kits (SuperArray, Frederick, MD, USA) were used to determine the regulation of gene expression corresponding to 113 genes involved in extracellular matrix remodeling (Cat
No OHS-013) and angiogenesis (Cat No OHS-024). Briefly, total RNA (3 $\mu$ g) was reverse-transcribed into cDNA, which was transcribed into Biotin-16-dUTPlabeled cRNA Probe with the use of TrueLabeling-AMP (SuperArray), according to the manufacturer's protocol. Hybridization was carried out by incubation of the membranes with Biotin-labeled cRNA probes at $60^{\circ} \mathrm{C}$ overnight. After washing, the membranes were incubated with alkaline phosphate-conjugated streptavidin and finally developed using the CDP-Star chemiluminescent substrate. The membranes then were scanned by Chemidoc XRS (Bio-Rad) and spot intensities quantified using the Quantity One software (Bio-Rad). The relative expression level of each gene was determined by comparing the signal intensity of each gene in the array after normalization to the signal of the $\beta$-actin house-keeping gene on the same membrane using the GEArray Analyser software. Genes with chemiluminescence intensity differing by $>2.0$ - or $<0.5$-fold between tissue collected at $\mathrm{T}_{1}$ and $\mathrm{T}_{2}$ time points related to the biopsies collected at $\mathrm{T}_{0}$, consistently occurring in at least five cases for the PL-group and the LA-group, were chosen for hierarchical clustering analysis. Following the logtransformation of the mean ratio of intensities for $\mathrm{T}_{1} / \mathrm{T}_{0}$ and $\mathrm{T}_{2} / \mathrm{T}_{0}$ for each gene of the PL- and LA-group, we then used the clustering analysis software, and the resulting expression map was visualized with Treeview using the average-linkage clustering algorithms (Eisen Lab, Stanford University, CA, USA). Genes with increased expression are indicated by green color, those with de- 
creased expression in red color. Yellow color indicates genes whose expression did not change between $\mathrm{T}_{0}$ and $\mathrm{T}_{1}$ or $\mathrm{T}_{2}$. Black color indicates genes that were not detected.

\section{Assessment of MMP2 and MMP9 Activity}

MMP2 and MMP9 activities in biopsy samples were assessed by an immunocapture assay using a commercially available kit according to the manufacturer's protocol (Amersham Biosciences, Piscataway, NJ, USA), using 96-well microtitre plates coated against MMP2 and MMP9. Active MMPs were captured from biopsy lysates (50 $\mu \mathrm{g}$ protein) incubated overnight at $4^{\circ} \mathrm{C}$. Individual wells then were washed, and $50 \mu \mathrm{L}$ of the assay buffer were added to each well. The detection process involved the addition of $50 \mu \mathrm{L}$ of the detection reagent to all wells and incubation at $37^{\circ} \mathrm{C}$ for 3-4 $\mathrm{h}$ before reading the absorbance at $405 \mathrm{~nm}$ using an ELISA plate reader (Sunrise, Tecan, Milan, Italy). Concentrations of active MMPs were extrapolated from the standard curve, and the activity was calculated as the rate of change in absorbance at $405 \mathrm{~nm}$ per hour and expressed as units per $\mathrm{mg}$ of total protein $(\mathrm{U} / \mathrm{mg})$.

\section{Human Matrix Metalloproteinase and Angiogenesis Protein Arrays}

Protein arrays for human matrix metalloproteinase (MMP2, MMP9 and TIMP1, TIMP2) and angiogenesis (PDGF$\mathrm{BB}, \mathrm{b}-\mathrm{FGF}, \mathrm{VEGF}-\beta$ ) were used to analyze the biopsy lysates. The IL-1 $\beta$, IL-6, $\mathrm{TNF} \alpha$ were assessed in plasma by means of the multiplex sandwich ELISA kit (SearchLight, Pierce Biotechnology, Rockford, IL, USA), according to the manufacturer's instructions. Results are expressed as ng/mg protein for biopsy and as $\mathrm{ng} / \mathrm{mL}$ for plasma samples.

\section{Clinical Analysis of Wounds}

Clinical analysis of the wounds was carried out using the mouse-eye software (Taylor R, Salford, UK, http:/ / www. hope-academic.org.uk/staff/rtaylor/) using the Eco-Doppler, oxymetry transcute instrument. The area of wounds was determined before $\left(\mathrm{T}_{0}\right)$ and after $14\left(\mathrm{~T}_{14}\right)$ and $40\left(\mathrm{~T}_{40}\right)$ days from the onset of the $\mathrm{HBO}$ therapy. Results are expressed as variation of the percentage of wound areas at $T_{14}$ and $T_{40}$ and are related to the basal values at $T_{0}$.

\section{Statistical Analysis}

The Kruskal-Wallis and Mann-Whitney non-parametric statistical tests were employed to assess the significance of the differences in the concentration and activity of MMPs and angiogenic/ inflammatory factor levels between the time points and between the groups. The $P$ values $<0.05$ were considered statistically significant. All statistical analyses were performed using SPSS for Windows version 11.0 (SPSS, Chicago, IL, USA).

\section{RESULTS}

\section{Effect of LA on Extracellular Matrix and Angiogenesis-Related Gene Expression Profile}

Pathway-specific microarrays for matrix remodeling and angiogenesis were utilized to explore changes in the expression of selected genes. Figure 1 shows the average changes in human ECM adhesion molecule genes (left panel) and genes involved in the angiogenic process (right panel). In the PLgroup, $\mathrm{HBO}$ treatment enhanced gene expression of most of ECM molecules, $20 / 28(71 \%)$ genes coding for adhesion molecules, and $50 \%$ of genes coding for ECM proteins, including that for metalloproteinases, and their inhibitors which were upregulated at the time point $\mathrm{T}_{1}$. The upregulated genes observed at $\mathrm{T}_{1}$ were consistently repressed $(30 / 40$, $75 \%$ ) at the 14 th $\mathrm{HBO}$ session $\left(\mathrm{T}_{2}\right)$. Notably, the MMP9 gene expression was upregulated at $\mathrm{T}_{1}$, then dropped to the basal value at $T_{2}$. No changes in gene expression were found for MMP2 and MMP3 at the first evaluation, with downregulation at the next time point. Similarly, LA supplementation induced expression of ECM molecules (21/28 genes for adhesion molecules; 7/12 genes for ECM proteins) at the first evaluation, then repressed them (32/40, $80 \%$ ) at the next time point. Expression of the MMP2 gene was strongly upregulated at $\mathrm{T}_{2}$. Conversely, LA supplementation markedly repressed MMP3 and MMP9 expression.

Expression profile analysis of angiogenesis-related genes revealed upregulation of genes $(32 / 42,76 \%)$ coding for growth factors, cytokines, transcription factors, and proteases in the PL-group at $\mathrm{T}_{1}$. However, at prolonged HBO exposure, $28 / 42(67 \%)$ upregulated or unchanged genes were repressed. In the LA-group, 52\% of angiogenesis-related genes were downregulated at $\mathrm{T}_{1}$. As shown in Figure 1 (right panel), downregulation was observed for genes coding growth factors, 10/15 (67\%); cytokines and chemokines, $1 / 9(11 \%)$; transcription factors, $4 / 7$ (57\%); and proteases, 8/11 (73\%). The gene repression was more evident at $\mathrm{T}_{2}(69 \%)$. LA supplementation reduced the expression of VEGF- $\beta$ and IL- 6 . It is noteworthy that PDGF-BB, IL-1 $\beta$, and IL- 8 were unchanged or were downregulated in the PL-group, while they were upregulated in the LA-group.

\section{Human Matrix Metalloproteinase, Inflammation, and Angiogenesis- Related Protein Levels}

The microarray analysis evidenced that the MMP2 and MMP9 gene expression was modulated differently by $\mathrm{HBO}$ therapy alone or in combination with LA. Because of their important role in the healing process $(13,14)$, the differential expression was confirmed by protein levels assayed in the biopsy. Because the MMPs activity is related strictly to the level of their inhibitors, TIMP1 and TIMP2 protein levels also were assessed. ELISA assay was used to validate the differential mRNA expression levels of three selected genes mainly involved in the angiogenic process. These genes are b-FGF, VEGF- $\beta$, and PDGF-BB, which were identified by functional cluster analysis. Differential expression of three 


\section{Extracellular Matrix}

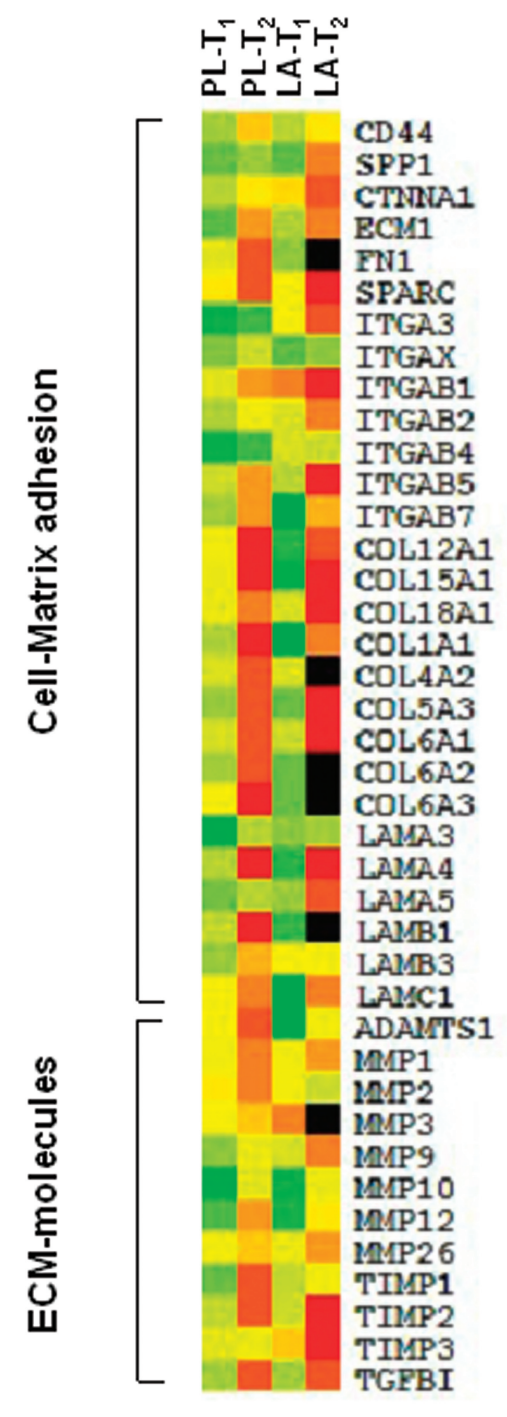

\section{Angiogenesis}

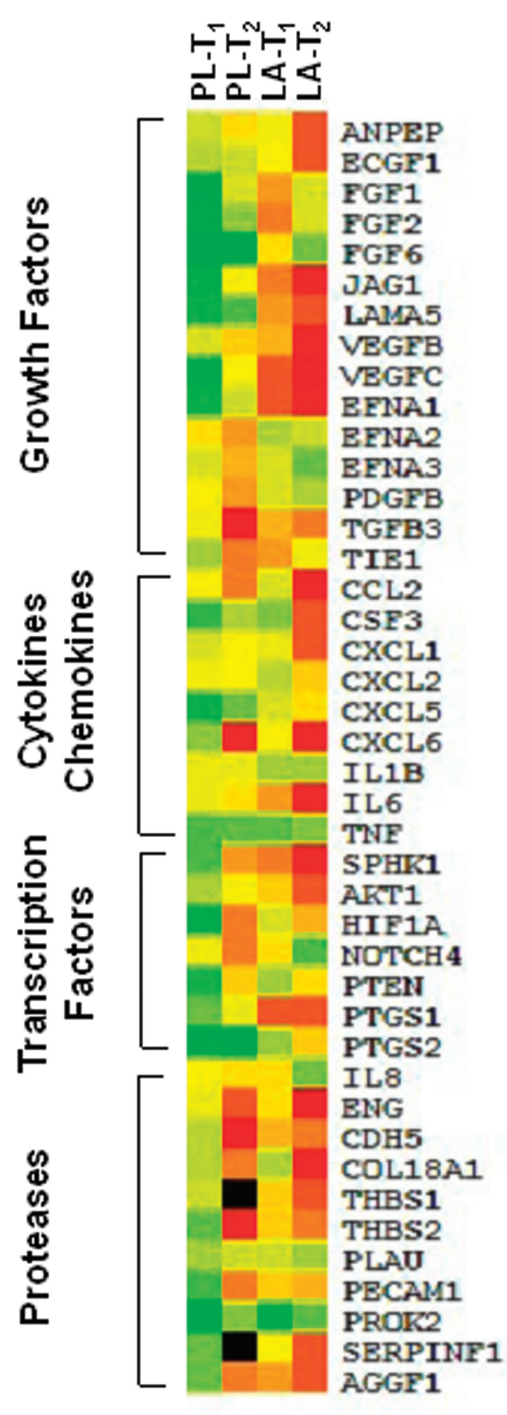

Figure 1. Representative gene expression patterns of selected genes from 113 genes involved in extracellular matrix remodeling (left panel) and angiogenesis (right panel). In five cases for PL-group and LA-group, chemiluminescence intensity corresponding to individual genes, differing by $>2.0$ - or $<0.5$-fold between tissue collected at $T_{1}$ and $T_{2}$ time points related to samples collected at $\mathrm{T}_{0}$ was chosen for the hierarchical clustering analysis. Individual genes are listed vertically. Relative normalized expression for each gene is represented by color intensity (green, overexpression; yellow, no expression change; red, reduced expression; black, gene not detected).

other transcripts involved in wound inflammation IL-1 $\beta$, IL-6, TNF $\alpha$ were confirmed by ELISA analysis.

MMP2 and MMP9 protein levels were evaluated both as the total protein and as the active form. As shown in Figure 2A, both the total MMP2 and its active form decreased slightly following $\mathrm{HBO}$ treatment (PL-group). In the LA-group, total MMP2 levels as well as the level of the active protein were significantly increased at $T_{2}$, revealing increased
MMP2 $2_{\text {active }} / \mathrm{MMP} 2_{\text {total }}$ ratio (Table 2). An opposite trend was observed for MMP9, whose expression and activity were induced slightly by HBO therapy. LA supplementation reduced the total MMP9 and its active form (Figure 2B), revealing reduced $\mathrm{MMP9} 9_{\text {active }} / \mathrm{MMP}_{\text {total }}$ ratio (Table 2). TIMP1 and TIMP2 tissue levels did not change significantly during $\mathrm{HBO}$ treatments and were not different between groups (Table 2). However, LA supplementation induced an increase of the MMP2/TIMP1 complex and the MMP2/TIMP2 complex, and a reduction of the MMP9/TIMP1 complex and the MMP9/TIMP2 complex at $\mathrm{T}_{2}$ (Table 2).

A slight increase in VEGF- $\beta$ and b-FGF levels was found in the PL-group following the $\mathrm{HBO}$ treatment. LA supplementation inhibited VEGF- $\beta$ and b-FGF expression but induced a significant increase of PDGF-BB level compared with the PLgroup (Figure 3).

As shown in Figure 4, no significant changes were observed for IL- $1 \beta$ and TNF $\alpha$ in both the LA-group and the PLgroup. Plasma levels of IL-6 increased following the $\mathrm{HBO}$ therapy in patients receiving placebo, most likely due to inflammatory events, while LA inhibited IL-6 expression.

\section{LA Promotes Progression of the Healing Process}

Daily oral administration of LA accelerated the healing process induced by the HBO therapy. As demonstrated in Figure 5, LA supplementation increased the reduction of the wound area relative to the PL-group, $17 \pm 43 \%$ compared with $6 \pm 10 \%, P<0.05$, at day 14 of the HBO therapy $\left(\mathrm{T}_{14}\right)$, and $31 \pm 42 \%$ compared with $18 \pm 16 \%, P<0.05$, at day $40\left(\mathrm{~T}_{40}\right)$.

\section{DISCUSSION}

Non-healing ulceration is a serious complication in diabetes mellitus, in conditions such as paralysis that inhibit movement, and in the elderly. Injuries often fail to heal because of persistently high concentrations of pro-inflammatory cytokines present in the wound sites, 
A
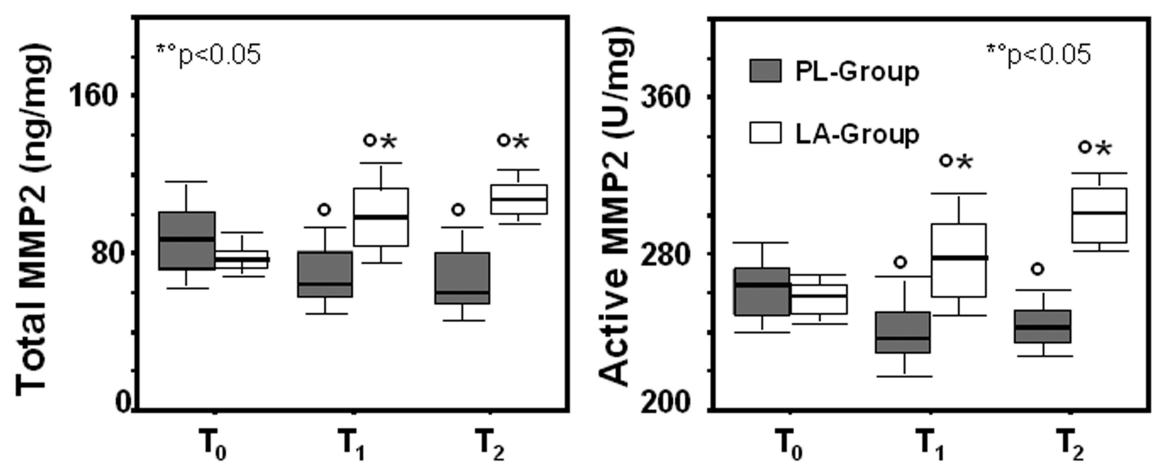

B
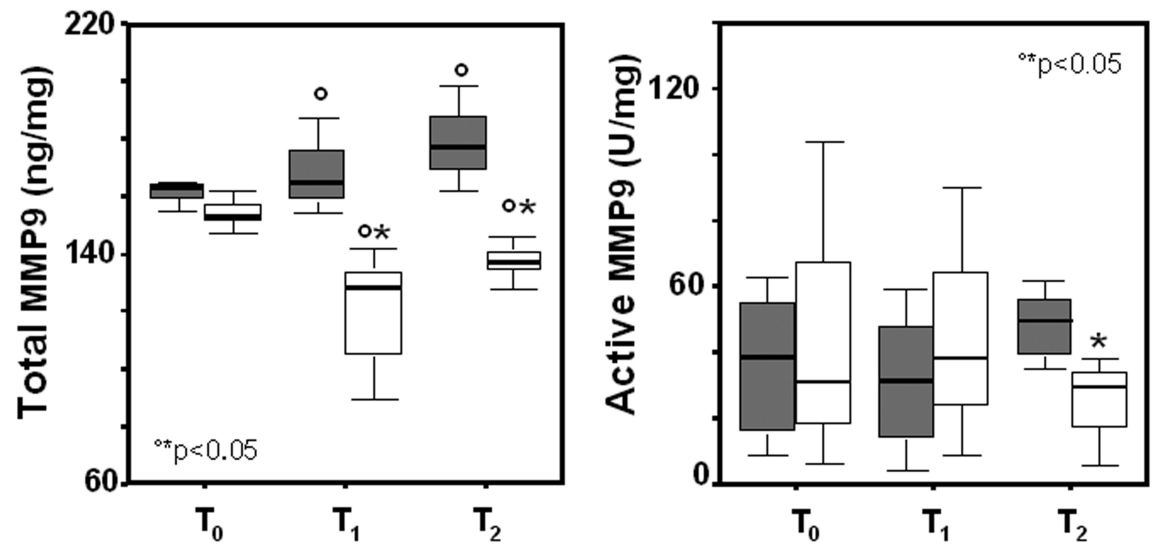

Figure 2. Box plots showing biopsy concentrations of the total and active MMP2 and MMP9 in LA-supplemented and control subjects undergoing HBO therapy. MMP2 (A) and MMP9 (B) levels were assessed in biopsy tissue of supplemented (LA-group) and nonsupplemented (PL-group) subjects at the first HBO session $\left(\mathrm{T}_{0}\right)$, at the seventh $\mathrm{HBO}$ session $\left(T_{1}\right)$, and at day 14 of HBO therapy $\left(T_{2}\right)$. Results are expressed as $n g / m g$ total protein. The lines in the boxes represent the median values. Lines extend to the minimum and maximum values, excluding the outliers (circles). ${ }^{\circ} \mathrm{T}_{1}$ and $\mathrm{T}_{2}$ compared with $\mathrm{T}_{0}$; ${ }^{*} \mathrm{LA}$-group compared with PL-group, $P<0.05$.

leading to high concentration of proteases. These in turn degrade several growth factors and matrix proteins that are essential for normal wound healing $(15,16)$. In particular, the transition from chronic to acute or fully restored functional connective tissue is affected by these factors, and this represents a major interest in the treatment of chronic ulceration (17). Besides the new therapeutic strategies such as local treatment with growth factors (18) or replacement with skin substitutes, local increase in the oxygen gradient by HBO therapy is an efficient approach. Recently, we observed that LA supplementation in association with $\mathrm{HBO}$ treatment further improved the healing process after 40 days posttherapy, determining a marked reduction in the wound, which in some cases resulted in a total remission (12). Using the microarray analysis, genes involved in extracellular matrix remodeling and angiogenesis were evaluated. Genes coding for growth factors, cytokines, cell-matrix adhesion molecules, and proteases were expressed highly in the chronic wounds.

Oxygenation induced overexpression of almost all of these genes at the first week of $\mathrm{HBO}$ treatment. At prolonged oxygen exposure some of them were repressed. Interestingly, an opposite modulation of MMP2 and MMP9 gene expression was exerted by $\mathrm{HBO}$ therapy alone or by $\mathrm{HBO}$ treatment combined with LA. Therefore, the validation of the MMP2 and MMP9 gene expression was assessed by the determination of their protein levels and activities. The MMPs activity is known to be inhibited by the binding of TIMPs as a 1:1 molar ratio, so the activity of MMPs is related strictly to the level of TIMPs. The controlled balance of MMPs and their inhibitors is necessary for a regular repair process. A shift toward a higher MMP2/TIMP1 and TIMP2 ratios was found in the LA-group, resulting in an increase of MMP2 activity. The enhanced MMP2 activity may present additional advantages during wound healing. MMP2 not only regulates the turnover of ECM but also exerts anti-inflammatory effects via the monocyte chemoattractant protein-3 (MCP-3), a chemokine that promotes leukocyte chemotaxis (19). MMP2 is the most efficient MMP to cleave and inactivate MCP-3, which results not only in blocking the initiation of an inflammatory response but also completely abrogates possible pre-existing inflammation (19).

In contrast, lowered MMP9/TIMP1 and TIMP2 ratios were found in the LAgroup, and this was associated with a reduction of the MMP9 activity. Active MMP9 does not cleave MCP-3, but cleaves and activates the pro-inflammatory cytokines IL-1 $\beta$ and IL-8, promoting their activity (20), which results in enhanced leukocytes influx and increased inflammation. It is known that MMP9 preferentially degrades the extracellular matrix during the early phase of the healing process. MMP9 is induced in the inflammatory phase in keratinocytes, 
Table 2. MMPs active/total ratio and the MMPs/TIMPs-complex in LA-supplemented and non-supplemented subjects undergoing HBO therapy.

\begin{tabular}{|c|c|c|c|c|c|c|}
\hline \multirow[b]{2}{*}{ Biopsy $^{a}$} & \multicolumn{3}{|c|}{ PL-Group } & \multicolumn{3}{|c|}{ LA-group } \\
\hline & $\mathrm{T}_{0}$ & $\mathrm{~T}_{1}$ & $\mathrm{~T}_{2}$ & $\mathrm{~T}_{0}$ & $\mathrm{~T}_{1}$ & $\mathrm{~T}_{2}$ \\
\hline MMP2act/MMP2tot & $0.69 \pm 0.27$ & $0.60 \pm 0.56$ & $0.46 \pm 0.66$ & $0.47 \pm 0.55$ & $0.92 \pm 0.87^{b}$ & $0.74 \pm 0.22^{b}$ \\
\hline MMP9act/MMP9tot & $0.22 \pm 0.03$ & $0.16 \pm 0.03$ & $0.21 \pm 0.04$ & $0.27 \pm 0.28$ & $0.34 \pm 0.25$ & $0.13 \pm 0.14^{b}$ \\
\hline TIMP1 & $99 \pm 35$ & $83 \pm 44$ & $104 \pm 29$ & $95 \pm 18$ & $88 \pm 47$ & $81 \pm 15$ \\
\hline TIMP2 & $417 \pm 147$ & $419 \pm 120$ & $437 \pm 116$ & $362 \pm 138$ & $334 \pm 136$ & $310 \pm 131$ \\
\hline MMP2/TIMP1 & $1.0 \pm 0.8$ & $0.9 \pm 0.5$ & $0.5 \pm 0.1^{b}$ & $1.7 \pm 0.5$ & $4.0 \pm 3.7^{b}$ & $4.8 \pm 3.0^{b}$ \\
\hline MMP2/TIMP2 & $2.3 \pm 2.2$ & $6.4 \pm 6.4$ & $2.0 \pm 1.6$ & $2.2 \pm 2.5$ & $2.0 \pm 2.5$ & $6.1 \pm 1.9^{b}$ \\
\hline MMP9/TIMPI & $1.6 \pm 0.1$ & $2.3 \pm 1.3$ & $1.7 \pm 0.6$ & $2.5 \pm 0.6$ & $2.4 \pm 1.5$ & $1.4 \pm 0.8^{b}$ \\
\hline MMP9/TIMP2 & $3.4 \pm 3.1$ & $17.1 \pm 7.3^{\mathrm{b}}$ & $5.9 \pm 3.8^{b}$ & $3.2 \pm 3.6$ & $3.4 \pm 3.8$ & $2.1 \pm 3.8^{\mathrm{b}}$ \\
\hline
\end{tabular}

a Results are expressed as $\mathrm{ng} / \mathrm{mg}$ total protein, and represented as mean $\pm \mathrm{SD}$.

${ }^{b} P<0.05, T_{1}$ and $T_{2}$ time point versus $T_{0}$ time point.

occurring within the scar areas of the tissue at maximum levels two weeks after the injury, with a decrease to basal level between two and four weeks. This coincides with the time at which angiogenesis would occur to provide the developing tissue with oxygen and nutrients $(6,21)$.

Because MMP2 expression occurs later after the injury; this protease is more likely to be involved in tissue structural changes rather than in the process of angiogenesis (21). Thus, the selective induction of MMP2 and inhibition of MMP9 by LA may promote wound healing not only by inducing cell migration but also by minimizing the associated inflammatory events.

The transient appearance of MMP transcripts in the distinct basal cells of the hyperproliferative epithelium implies that the expression of epithelial MMPs during normal excisional wound repair is regulated efficiently both temporally and spatially. Such efficient control could be mediated by the action of growth factors and cytokines that are present transiently during the inflammatory phases of the repair $(22,23)$. Self-resolving inflammation is a normal and necessary prerequisite to fibroblast activation and net matrix synthesis. In contrast, prolonged expression of the granulocytesmacrophage colony stimulating factor results in sustained inflammation via prolonged residence of neutrophils and monocytes, resulting in abrogation of normal wound healing (24). High levels of chemokines and cytokines were observed in biopsies collected from chronic ulcers, and HBO therapy enhanced their expression. LA supplementation markedly repressed expression of inflammatory genes. Downregulation of IL-6 mRNA, observed at day 14 of LA supplementation, was associated with reduced plasma levels of the IL-6 protein. Conversely, an increase in mRNA expression of IL-1 $\beta$ and IL- 8 was not accompanied by corresponding changes in the protein levels in the LA-group.

IL-6, IL-1 $\beta$, and IL-8 serve as pro-inflammatory cytokines and their inhibition contributes to suppression of the inflammatory process. Moreover, IL-8 not only mediates leukocytes infiltration, but also may participate in wound re-epitheliazation and angiogenesis $(25,26)$. Both pro-inflammatory and anti-inflammatory cytokines are involved in the initiation, control, and termination of the cellular events that occurs at each stage of wound healing, by their chemoattractant activity and their ability to stimulate cellular proliferation (27). Growth factors are considered to be peptide mediators in cell proliferation, cell cycling, and apoptosis. Among the pro-angiogenic factors involving in wound healing, bFGF and VEGF appear to be of primary importance $(28,29)$. Elevated level of VEGF was found in chronic wounds (30).
Several epidermal and dermal factors, including TGFs, EGF $(31,32)$, and TNF $\alpha$ (32), and hypoxia (33) have been shown to enhance VEGF expression at chronic wound sites. In our system, HBO therapy induced expression at the mRNA and protein level of the b-FGF and VEGF- $\beta$. Gene expression for VEGF- $\alpha$ was not observed either at basal level and its expression was not induced by $\mathrm{HBO}$ treatment in either the PL-group or the LA-group. The angiogenic action of $\mathrm{HBO}$ therapy has been observed previously $(34,35)$. Increased VEGF- $\beta$ production by $\mathrm{HBO}$ treatment was observed in a wound model, whereas induction of bFGF and HGF without affecting VEGF was found in the ischemic hind limbs (36). Despite the increased expression of b-FGF and VEGF- $\beta$, the high proteolytic activity in this environment results in their degradation (30). Taking into account the observation from Keyt et al. that the proteolysis of VEGF impairs its biological activity, in the chronic wound environment, VEGF-protease interaction would restrain neovascularization (37).

As LA promotes wound healing, it would be expected even to increase angiogenesis by the expression of growth factors. However, these were actually downregulated, suggesting that the alteration of the protease and inflammatory cytokine expression has a greater effect on the healing process. An LA-mediated inhibitory effect on proliferation and 

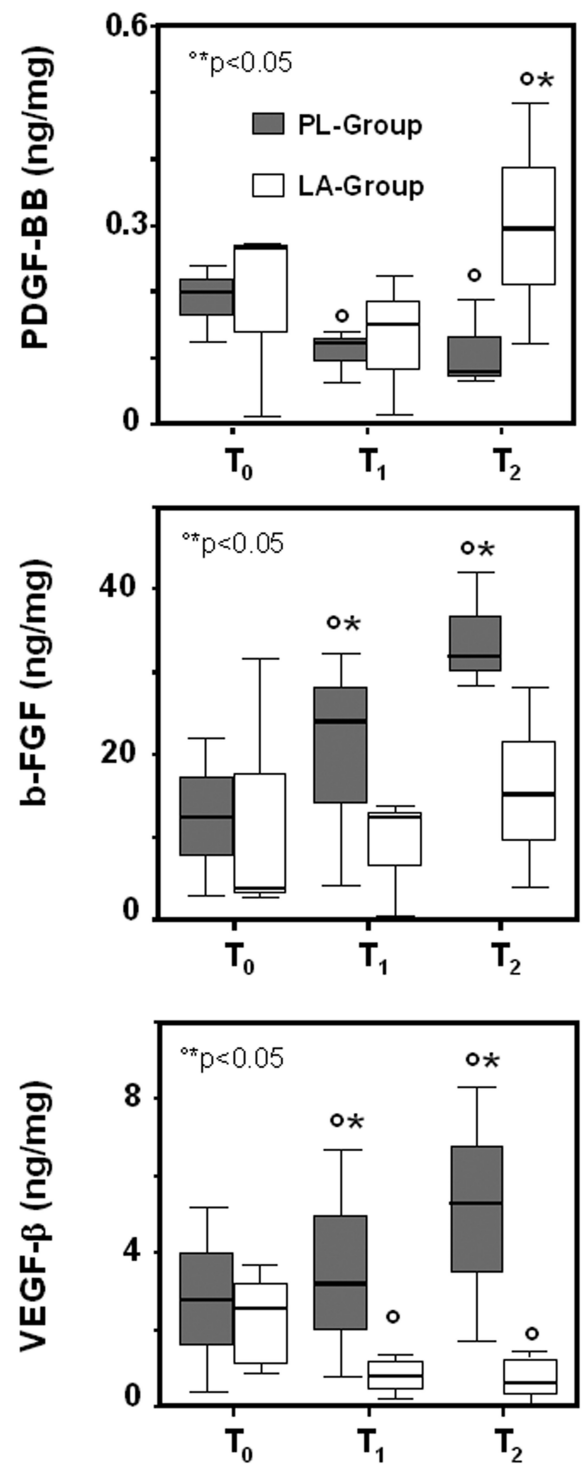

Figure 3. Box plots showing biopsy concentrations of PDGF-BB, b-FGF, and VEGF- $\beta$ in LA-supplemented and control subjects undergoing $\mathrm{HBO}$ therapy. The PDGF-BB, b-FGF, VEGF- $\beta$ protein levels were assessed in biopsy tissue of supplemented (LA-group) and non-supplemented (PL-group) subjects at the first $\mathrm{HBO}$ session $\left(\mathrm{T}_{0}\right)$, at the seventh $\mathrm{HBO}$ session $\left(T_{1}\right)$, and at day 14 of HBO therapy $\left(T_{2}\right)$. Results are expressed as $n g / m g$ total protein. The lines in the boxes represent the median values. Lines extend to the minimum and maximum values, excluding the outliers (circles). ${ }^{\circ} \mathrm{T}_{1}$ and $\mathrm{T}_{2}$ versus $\mathrm{T}_{0}$; * LA-group compared with PL-group, $P<0.05$.
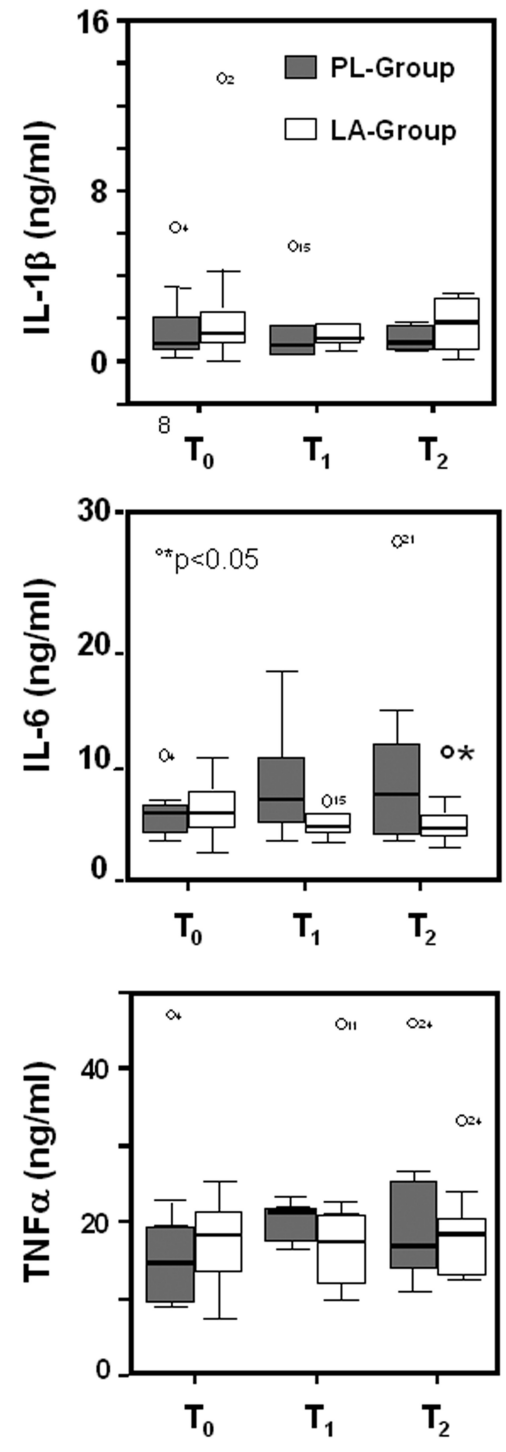

Figure 4. Box plots showing plasma concentrations of IL-1 $\beta, I L-6$, and TNF $\alpha$ proteins in LA-supplemented and control subjects undergoing $\mathrm{HBO}$ therapy. IL-1 $\beta$, $\mathrm{IL}-6$, and TNF $\alpha$ protein levels were assessed in plasma of supplemented (LA-group) and non-supplemented (PLgroup) subjects at the first $\mathrm{HBO}$ session $\left(T_{0}\right)$, at the seventh $\mathrm{HBO}$ session $\left(\mathrm{T}_{1}\right)$, and day 14 of HBO therapy $\left(T_{2}\right)$. Results are expressed as $\mathrm{ng} / \mathrm{mL}$. The lines in the boxes represent the median values. Lines extend to the minimum and maximum values, excluding the outliers (circles). ${ }^{\circ} \mathrm{T}_{1}$ and $\mathrm{T}_{2}$ versus $\mathrm{T}_{0}$; ${ }^{*} \mathrm{LA}$-group compared with $\mathrm{PL}$-group, $P<0.05$.

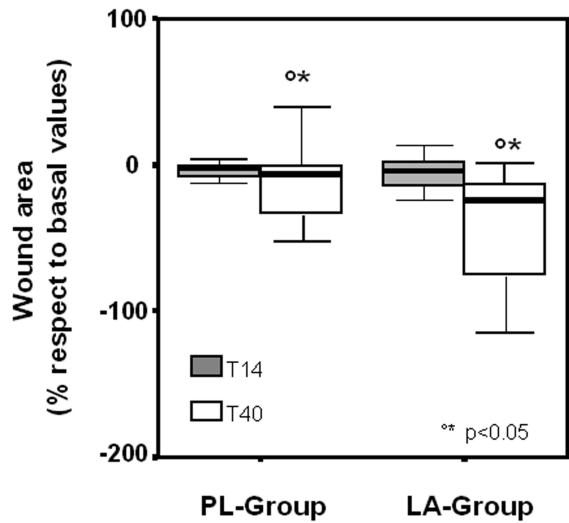

Figure 5. Clinical evaluation of wounds in LA-supplemented (LA-group) and control subjects ( $\mathrm{PL}$-group) undergoing $\mathrm{HBO}$ therapy. The area of lesions, calculated using the 'mouse-eye' software, was analyzed at 14 days $\left(\mathrm{T}_{14}\right)$ and 40 days $\left(\mathrm{T}_{40}\right)$ of $\mathrm{HBO}$ therapy. Data are expressed as percentage of area variation, evaluated at $\mathrm{T}_{14}$ and $T_{40}$, and related to the basal value $\left(\mathrm{T}_{0}\right)$ measured prior to the therapy.

apoptosis has been found in endothelial cells (38). The inhibition of apoptosis was paralleled by reduction of NF- $\kappa B$, and its promoter activity is suppressed by LA in a concentration-dependent manner (39). Furthermore, LA attenuates the DNAbinding activity of NF- $\mathrm{KB}$ resulting in an inhibition of several inflammatory and proangiogenic genes, including IL-6, MMP9, and VEGF $(39,40)$. Thus, the LAinduced NF- $\kappa$ B inhibition may contribute primarily to suppress the inflammatory process and the protease activity inhibiting the degradation of angiogenic factor, which is a contributing factor in chronic wound healing failure.

A number of different growth factors are thought to simulate angiogenesis during wound healing, including those that, in addition to acting on endothelial cells, also stimulate mesenchymal/epithelial cells such as platelet-derived growth factor (PDGF), which is a chemotactic factor for monocytes and fibroblasts regulating angiogenesis (41). PDGF accelerates tissue granulation and extracellular matrix deposition (42). We found that LA supplementation significantly induces 
mRNA expression of PDGF-BB as well as the level of the protein. Conversely, reduction in PDGF-BB mRNA expression and lower PDGF-BB protein levels were observed in the PL-group. Greenhalgh et al. (42), and Tsuboi and Rifkin (43) showed earlier that impaired healing could be reversed by polypeptide growth factors, including FGFs and PDGF-BB, leading to the successful use of recombinant PDGF-BB in the treatment of human diabetic ulcers. PDGF-BB promotes the inflammatory and proliferative/matrix deposition phases of repair without disrupting the normal sequence of events, in contrast to other growth factors applied pharmacologically, such as members of the FGF family and the transforming growth factor- $\beta$ (TGF- $\beta$ ), which also alter the normal healing process $(44,45)$.

Taken together, we show that pro-inflammatory factors are highly expressed in impaired ulcers. Chronic inflammation and bacterial contamination establish a positive autocrine feedback loop maintaining the chronic wound state. Compromised tissue oxygenation or wound hypoxia is viewed as a major factor that limits the healing process as well as suppression of the level of infection. Thus, oxygen supply, which is necessary to stimulate tissue regeneration, is required for tissue healing. We present data documenting that LA supplementation downregulates the chronic inflammatory state, changing the protease/anti-protease levels within the wound microenvironment. Decrease in the MMP9 expression and MMP2 upregulation, together with increased levels of PDGF-BB, contribute significantly to acceleration of the dermal wound repair process suggesting a beneficial role of LA supplementation in the treatment of chronic wounds.

\section{ACKNOWLEDGMENTS}

We thank MDM, Milano, Italy for the generous gift of $\alpha$-Lipoic acid capsules (Byodinoral-300).

\section{REFERENCES}

1. Martin P. (1997) Wounds healing-aiming for perfect skin regeneration. Science. 276:75-81.
2. Singer AJ, Clark RA. (1999) Cutaneous wound healing. N. Engl. J. Med. 341:738-46.

3. Yager DR, Nwomeh BC. (1999) The proteolytic environment of chronic wounds. Wound Rep. Regen. 7:433-41.

4. Nagase H, Visse R, Murphy G. (2006) Structure and function of matrix metalloproteinases and TIMPs. Cardiovasc. Res. 69:562-73.

5. Visse R, Nagase H. (2003) Matrix metalloproteinases and tissue inhibitors of metalloproteinases: structure, function, and biochemistry. Circ. Res. 92:827-39.

6. Madlener M, Parks WC, Wermer S. (1998) Matrix metalloproteinases (MMPs) and their physiological inhibitors (TIMPs) are differentially expressed during excisional skin wound repair. Exp. Cell Res. 242:201-10.

7. Mast BA, Schultz GS. (1996) Interactions of cytokines, growth factors, and proteases in acute and chronic wounds. Wound Repair Regen. 4:411-20.

8. Ciaravino ME, Friedell ML, Kommerlocher TC. (1996) Is hyperbaric oxygen a useful adjuvant in the management of problem lower extremity wounds? Ann. Vasc. Surg. 10:558-62.

9. Abidia A et al. (2003) Role of hyperbaric oxygen therapy in ischemic, diabetic, lower-extremity ulcers: double-blind randomized controlled trial. Eur. J. Vasc. Endovasc. Surg. 25:513-18.

10. La Van FB, Hunt TK. (1990) Oxygen and wound healing. Clin. Plast. Surg. 17:463-72.

11. Kinighton DR, Halliday B, Hunt TK. (1986) Oxygen as an antibiotic: a comparison of the effects of inspired oxygen concentration and antibiotic administration on in vivo bacterial clearance. Arch. Surg. 121:191-95.

12. Alleva R, Nasole E, Di Donato F, Borghi B, Neuzil J, Tomasetti M. (2005) $\alpha$-Lipoic acid supplementation inhibits oxidative damage, accelerating chronic wound healing in patients undergoing hyperbaric oxygen therapy. Biochem. Biophys. Res. Commun. 333:404-10.

13. Manuel JA, Gawronska-Kozak B. (2006) Matrix metalloproteinase 9 (MMP-9) is upregulated during scarless wound healing in athymic nude mice. Matrix Biol. 25:505-14.

14. Hsu JY, McKeon R, Goussev S, Werb Z, Lee JU, Trivedi A, Noble-Haeusslein LJ. (2006) Matrix metalloproteinase-2 facilitates wound healing events that promote functional recovery after spinal cord injury. J. Neurosci. 26:9841-50.

15. Amstrong DG, Jude EB. (2002) The role of matrix metalloproteinases in wound healing. J. Am. Podiatr. Med. 92:12-8.

16. Lobmann R, Ambrosch A, Schultz G, Waldmann K, Schiweck S, Lehnert, H. (2002) Expression of matrix-metalloproteinases and their inhibitors in the wounds of diabetic and non-diabetic patients. Diabetologia. 45:1011-6.

17. Singer A, Clark RA. (1999) Cutaneous wound healing. New Engl. J. Med. 341:738-46.

18. Papanas N, Maltezos E. (2007) The diabetic foot: established and emerging treatments. Acta Clin. Belg. 62:230-8.
19. McQuibban GA, Gong JH, Wong JP, Wallace JL, Clark-Lewis I, Overall CM. (2002) Matrix metalloproteinases processing of monocyte chemoattractant proteins generates CC chemokine receptor antagonists with anti-inflammatory properties in vivo. Blood. 100:1160-67.

20. Van Den Steen PE, Wuyts A, Husson SJ, Proost P Van Damme J, Opdenakker G. (2003) Gelatinase B/MMP-9 and neutrophil collagenase/MMP-8 process the chemokines human GCP-2/CXCL6, ENA-78/CXCL5 and mouse GCP-2/LIX and modulate their physiological activities. Eur. J. Biochem. 270:3739-49.

21. Gillard JA, Reed MWR, Buttle D, Cross SS, Brown NJ. (2004) Matrix metalloproteinases activity and immunohistochemical profile of matrix metalloproteinase-2 and -9 and tissue inhibitor of metalloproteinase-1 during human dermal wound healing. Wound Rep. Reg. 12:295-304.

22. Gailit J, Clark RAF. (1994) Wound repair in the context of extracellular matrix. Curr. Opin. Cell Biol. 6:717-25.

23. Engelhardt E, Toksoy A, Goebeler M, Debus S, Broecker EB, Gillitzer R. (1998) Chemokines IL8, GRO $\alpha$, MCP1, IP10 and Mi are sequentially and differentially expressed during phase-specific infiltration of leukocytes subsets in human wound healing. Am. J. Pathol. 153:1849-60.

24. Wetzler C, Kaempfer H, Stallmeyer B, Pfeilschifter J, Frank S. (2000) Large and sustained induction of chemokines during impaired wound healing in the genetically diabetic mouse: prolonged persistence of neutrophilis and macrophages during the late phase of repair. J. Invest. Dermatol. 115:245-53.

25. Michel G, Kemeny L, Peter RU, Beetz A, Ried C, Arenberger P, Ruzicka T. (1992) Interleukin-8 receptor-mediated chemotaxis of normal human epithelial cells. FEBS Lett. 305:241-43.

26. Rennekampff HO, Hansbrough JF, Kiessig V, Dore C, Sticherling M, Schroeder JM. (2000) Bioactive interleukin- 8 is expressed in wounds and enhances wound healing. J. Surg. Res. 93:41-54.

27. Baker EA, Leaper DJ. (2000) Proteinases, their inhibitors, and cytokine profiles in acute wound fluid. Wound Rep. Reg. 8:392-8.

28. Pakele R, Watanabe T, Benedict CR. (2002) Induction of endothelial cell proliferation by angiogenic factors released by activated monocytes. Cardiovasc. Radiat. Med. 3:95-101.

29. Pepper MS, Mandriota SJ, Jeltsch M, Kumar V, Alitalo K. (1998) Vascular endothelial growth factor (VEGF)-C synergizes with basic fibroblast growth factor and VEGF in the induction of angiogenesis in vitro and alters endothelial cell extracellular proteolytic activity. J. Cell Physiol. 177:439-52.

30. Lauer G et al. (2000) Expression and proteolysis of vascular endothelial growth factor is increased in chronic wounds. J. Invest. Dermatol. 115:12-8.

31. Detmar M et al. (1995) Keratinocyte-derived vascular permeability factor (vascular endothelial growth factor) is a potent mitogen for dermal mi- 
crovascular endothelial cells. J. Invest. Dermatol. 105:44-50.

32. Frank S, Hubner G, Breier G, Longaker MT, Greenhalgh DG, Werner S. (1995) Regulation of vascular endothelial growth factor expression in cultured keratinocytes. Implications for normal and impaired wound healing. J. Biol. Chem. 270:12607-13.

33. Detmar M, Brown LF, Berse B, Jackman RW, Elicker BM, Dvorak HF, Claffey KP. (1997) Hypoxia regulates the expression of vascular permeability factor/vascular endothelial growth factor (VPF/VEGF) and its receptors in human skin. J. Invest. Dermatol. 108:263-8.

34. Al-Waili NS, Butler GJ. (2006) Effects of hyperbaric oxygen on inflammatory response to wound and trauma: possible mechanism of action. Sci. World J. 6:425-41.

35. Sheikh AY, Gibson JJ, Rollins MD, Hopf HW, Hussain Z, Hunt TK. (2000) Effect of hyperoxia on vascular endothelial growth factor levels in a wound model. Arch. Surg. 135:1293-7.

36. Asano T, Kaneko E, Shinozaki S, Imai $Y$, Shibayama M, Chiba T, Ai M, et al. (2007) Hyperbaric oxygen induces basic fibroblast growth factor and hepatocyte growth factor expression, and enhances blood perfusion and muscle regeneration in mouse ischemic hind limbs. Circ. J. 71:405-11.

37. Keyt BA, Barleau LT, Nguyen HV, Chen H, Heinsoh H, Vandlen R, Ferrara N. (1996) The carboxyl-terminal domain (111-165) of VEGF is crucial for its mitogenic potency. J. Biol. Chem. 271:7788-95.

38. Artwohl M et al. (2007) R-(+)- $\alpha$-lipoic acid inhibits endothelial cell apoptosis and proliferation: involvement of Akt and retinoblastoma protein/E2F-1. Am. J. Physiol. 293:E681-9.

39. Hye-Soon K et al. (2007) $\alpha$-Lipoic acid inhibits matrix metalloproteinase-9 expression by inhibiting NF-кB transcriptional activity. Exp. Mol. Med. 39:106-13.

40. Karin M, Greten FR. (2005) NF-кB: Linking inflammation and immunity to cancer development and progression. Nat. Rev. Immunol. 5:749-59.

41. Shure D, Senior RM, Griffin GL, Deuel TF. (1992) PDGF AA homodimmers are potent chemoattractants for fibroblasts and neutrophils, and for monocytes activated by lymphocytes or cytokines. Biochem. Biophys. Res. Commun. 186:1519-24.

42. Greenhalgh DG, Sprugel KH, Murray MJ, Ross R. (1990) PDGF and FGF stimulate wound healing in the genetically diabetic mouse. Am. J. Pathol. 136:1235-46.

43. Tsuboi R, Rifkin DB. (1990) Recombinant basic fibroblast growth factor stimulates wound healing in healing-impaired db/cb mice. J. Exp. Med. 172:245-51.

44. Pierce GF, Tarpley D, Yanagihara TA, Mustoe GM, Thomason A. (1992) PDGF-BB, TGF- $\beta 1$, and basic FGF in dermal wound healing: neovessel and matrix formation and cessation of repair. Am. J. Pathol. 140:1375-88.

45. Crombleholme TM. (2000) Adenoviral-mediated gene transfer in wound healing. Wound Repair Regen. 8:460-72. 